\title{
Multimodal images of chronic branch retinal vein occlusion
}

\author{
Stephen G Schwartz \\ Armando Monroig \\ Harry W Flynn Jr \\ Department of Ophthalmology, \\ Bascom Palmer Eye Institute, \\ University of Miami Miller School \\ of Medicine, Miami, FL, USA
}

This article was published in the following Dove Press journal: International Medical Case Reports Journal 4 May 2017

Number of times this article has been viewed
Abstract: Two illustrative cases of chronic branch retinal vein occlusion are presented with multimodal imaging, including commercially available optical coherence tomography angiography. In these two patients, retinal ischemia and collateral vessels were well imaged without the need to use traditional fluorescein angiography. Optical coherence tomography angiography provides useful information for the diagnosis and management of patients with branch retinal vein occlusion and other retinal vascular diseases.

Keywords: branch retinal vein occlusion, optical coherence tomography angiography, spectral domain optical coherence tomography, multimodal imaging, BRVO management

\section{Introduction}

Branch retinal vein occlusion (BRVO) is a common retinal vascular disease that may lead to cystoid macular edema (CME), retinal ischemia, retinal neovascularization, and other complications. ${ }^{1}$ Spectral domain optical coherence tomography (SD-OCT) is important in the management of this entity. More recently, OCT angiography (OCT-A) has become available and has provided new insights for clinicians managing this disease. ${ }^{2}$

Using multimodal imaging, including OCT-A imaging with the commercially available Cirrus 5000 with AngioPlex (Zeiss, Jena, Germany), the pathologic features of chronic BRVO in two patients are demonstrated.

\section{Report of two cases Case I}

A 56 year-old female with a history of chronic BRVO left eye returned for scheduled follow-up, noting long-standing but stable blurred vision. She had been treated with intravitreal Avastin ${ }^{\circledR}$ (bevacizumab) (Avastin ${ }^{\circledR}$; Genentech, South San Francisco, CA, USA) and triamcinolone acetonide in the past, but no treatments for several years. On examination, best-corrected visual acuity was 20/40 in the left eye. Fundus examination revealed sclerotic vessels in the superotemporal quadrant with collaterals near the optic disc, as well as CME (Figure 1A). Humphrey visual field 24-2 testing revealed an inferior arcuate defect encroaching fixation (Figure 1B). SD-OCT revealed mild thickening centrally and atrophy superotemporally (Figure 1C). SD-OCT through the center of the macula revealed a prominent central cyst as well as temporal thinning (Figure 1D). The OCT-A retina slab $(6 \times 6 \mathrm{~mm})$ demonstrated marked capillary
Correspondence: Stephen G Schwartz Department of Ophthalmology, Bascom Palmer Eye Institute, 3880 Tamiami Trail North, Naples, FL 34103, USA

Tel + I 2396593937

Email sschwartz2@med.miami.edu 

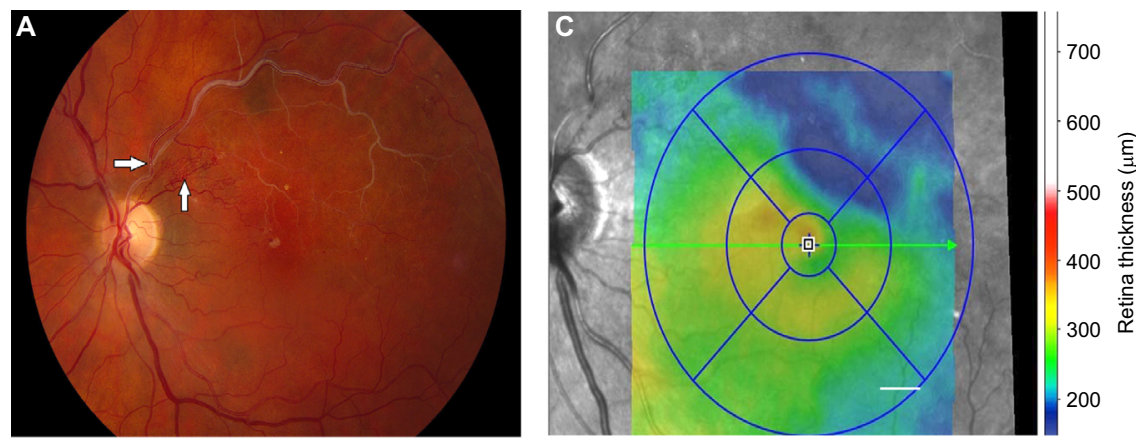

B

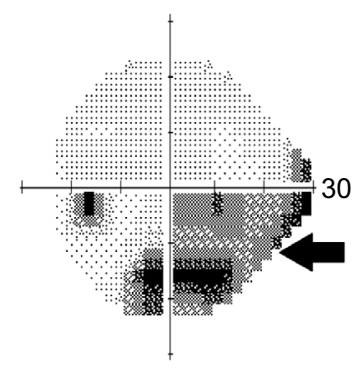

D

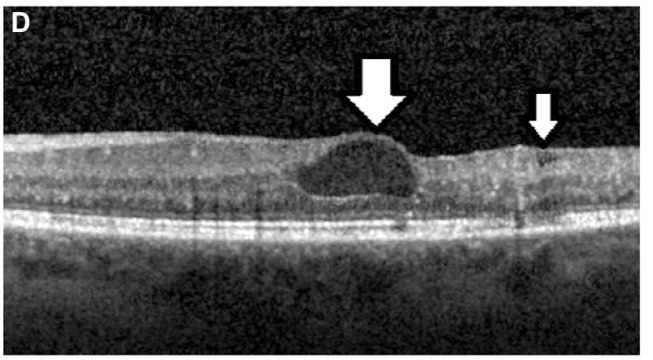

E

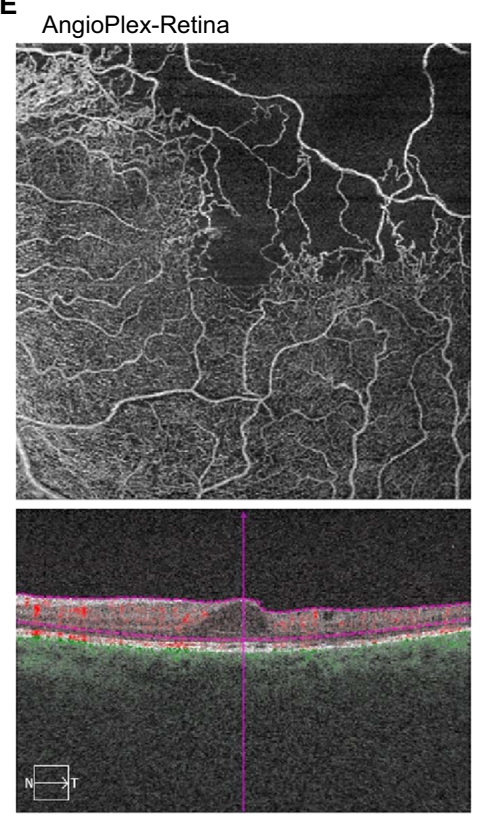

Figure I BRVO, left eye.

Notes: (A) Fundus photography demonstrated the site of the occlusion (horizontal arrow) and collateral vessels (vertical arrow). (B) Humphrey visual field 24-2 testing demonstrated an inferior arcuate defect encroaching fixation (arrow). (C) SD-OCT map demonstrated mild thickening centrally and atrophy superotemporally. (D) SD-OCT demonstrated a central macular cyst (larger vertical arrow) and temporal thinning (smaller vertical arrow). (E) OCT-A retina slab (6×6 mm) demonstrated profound capillary nonperfusion in the superotemporal quadrant, involving the foveal avascular zone.

Abbreviations: BRVO, branch retinal vein occlusion; OCT-A, optical coherence tomography-angiography; SD-OCT, spectral domain optical coherence tomography.

nonperfusion in the superotemporal macula, involving the foveal avascular zone (FAZ) (Figure 1E).

\section{Case 2}

A 52-year-old female with a history of chronic hemiretinal vein occlusion right eye presented with recurrent episodes of floaters and visual loss. She had been treated with scatter photocoagulation elsewhere about six months previously. On examination, best-corrected visual acuity was 20/25. Fundus examination revealed sclerotic veins inferotemporally and inferonasally. Scatter photocoagulation was evident inferotemporally. Collateral vessels temporal to the center of the macula and crossing the horizontal raphe were present (Figure 2A). Fluorescein angiography revealed areas of ischemia temporally and inferonasally, with collateral vessels temporal to the center of the macula (Figure 2B). Late frames revealed mild macular leakage and more prominent leakage inferiorly, consistent with retinal neovascularization (Figure 2C). SD-OCT through the center of the macula showed no frank CME (Figure 2D). The OCT angiography retina slab $(6 \times 6 \mathrm{~mm})$ demonstrated prominent collateral vessels temporal (and some nasal) to the foveal avascular zone, as well as capillary nonperfusion involving the inferior FAZ as well as inferotemporal to the center of the macula (Figure 2E).

\section{Discussion}

These two cases illustrate the utility of OCT-A in providing additional information in the management of patients with chronic BRVO. In case 1, OCT-A demonstrates capillary nonperfusion involving the FAZ, which correlates with the visual field defect encroaching fixation. This suggests that visual loss is due to both CME and macular ischemia and that further pharmacologic treatment of the CME might not benefit the patient. In case 2 , OCT-A demonstrates capillary nonperfusion and highlights the collateral vessels, which were poorly visualized on fundus photography but were visualized using fluorescein angiography. Case 2 also provides a comparison between OCT-A and fluorescein angiography, demonstrating concordance between the collateral vessels and the macular ischemia on each test.

The role of OCT-A in the management of BRVO is evolving. OCT-A may offer similar information to fluorescein angiography ${ }^{3}$ and can be obtained rapidly and without the need for dye injection. OCT-A is reported to image the FAZ well in patients with BRVO. ${ }^{4}$ However, the technology is currently expensive, and image quality depends on the patient's ability to fixate. ${ }^{5}$

As additional patients with acute and chronic BRVO, and other retinal vascular diseases, are imaged with OCT-A, the utility of this noninvasive imaging technology will become 

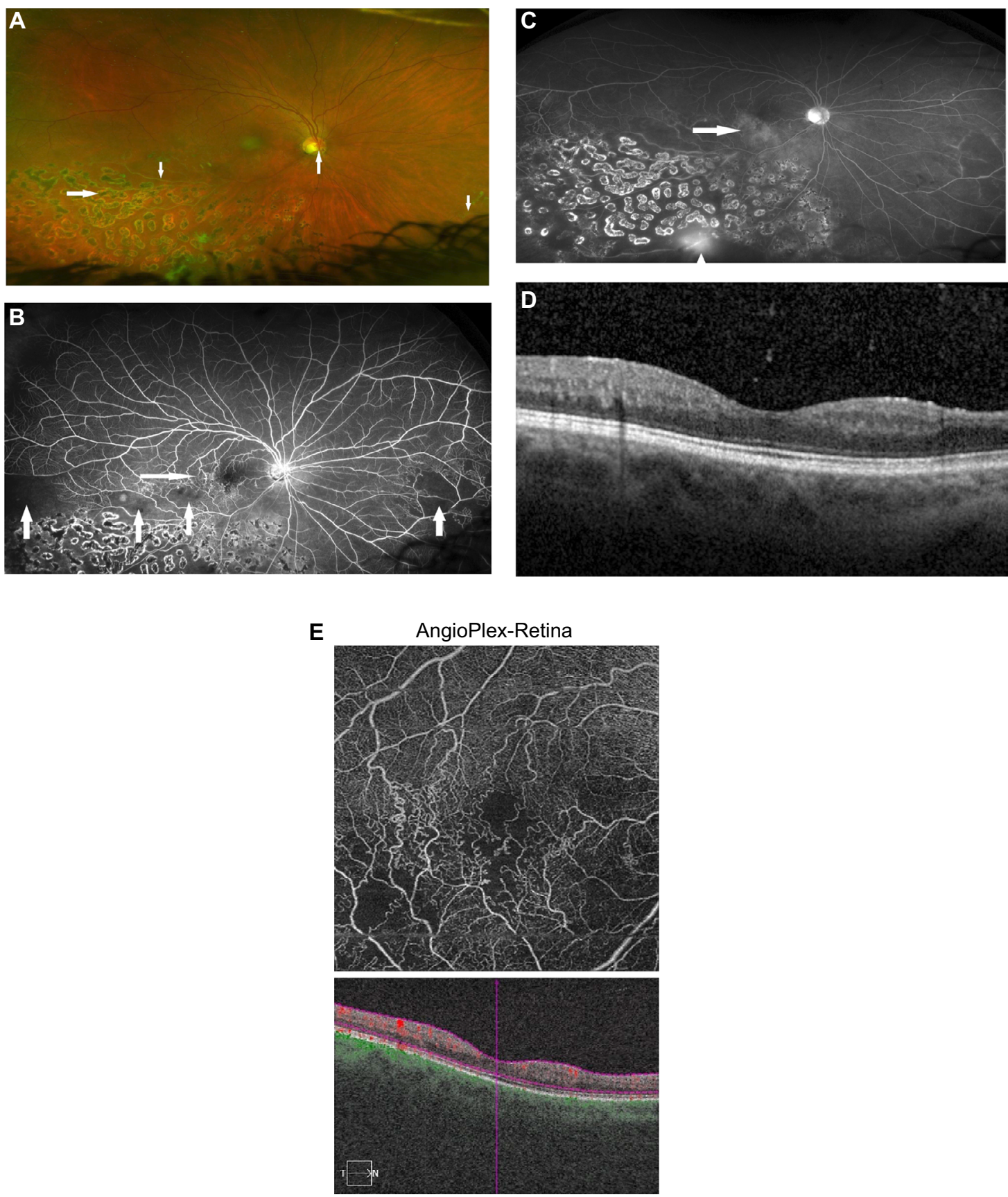

Figure 2 Hemiretinal vein occlusion, right eye.

Notes: (A) Fundus photography demonstrated the site of the occlusion at the disc (upward vertical arrow) and sclerotic veins in the inferotemporal and inferonasal quadrants (downward vertical arrows). Collateral vessels temporal to the center of the macula did not photograph well. Photocoagulation burns (horizontal arrow) are evident. (B) Fluorescein angiography demonstrated areas of capillary nonperfusion temporally and inferonasally (vertical arrows). Collateral vessels temporal to the macula were noted (horizontal arrow). (C) Fluorescein angiography late frames demonstrated mild macular leakage (horizontal arrow) and more prominent leakage inferiorly (vertical arrow). (D) SD-OCT demonstrated no frank cystoid macular edema. (E) OCT-A retina slab (6×6 mm) demonstrated prominent collateral vessels temporal to (and some nasal to) the center of the macula, as well as areas of capillary nonperfusion inferior to the fovea and inferotemporal to the fovea.

Abbreviations: OCT-A, optical coherence tomography-angiography; SD-OCT, spectral domain optical coherence tomography.

better understood and may help in screening or predicting visual outcomes.

\section{Acknowledgements}

Partially supported by NIH Center Core Grant P30EY014801 and an unrestricted grant from Research to Prevent Blindness. This manuscript has not been presented at any meeting.
Written informed consent has been provided by the patients to have the case details and any accompanying images published.

\section{Disclosure}

The authors report no conflicts of interest in this work. SGS has received consulting fees from Alimera Sciences unrelated to this work. 


\section{References}

1. Gregori NZ, Rattan GH, Rosenfeld PJ, et al. Safety and efficacy of intravitreal bevacizumab (Avastin) for the management of branch and hemiretinal vein occlusion. Retina. 2009;29(7):913-925.

2. Shahlaee A, Hong BK, Ho AC. Optical coherence tomography angiography features of branch retinal vein occlusion. Retin Cases Brief Rep. 2017;11(1):90-93.

3. Suzuki N, Hirano Y, Yoshida M, et al. Microvascular abnormalities on optical coherence tomography angiography in macular edema associated with branch retinal vein occlusion. Am J Ophthalmol. 2016;161:126-132.
4. Wons J, Pfau M, Wirth MA, et al. Optical coherence tomography angiography of the foveal avascular zone in retinal vein occlusion. Ophthalmologica. 2016;235(4):195-202.

5. Nobre Cardoso J, Keane PA, Sim DA, et al. Systematic evaluation of optical coherence tomography angiography in retinal vein occlusion. Am J Ophthalmol. 2016;163:93-107.

\section{Publish your work in this journal}

The International Medical Case Reports Journal is an international, peer-reviewed open-access journal publishing original case reports from all medical specialties. Previously unpublished medical posters are also accepted relating to any area of clinical or preclinical science. Submissions should not normally exceed 2,000 words or
Submit your manuscript here: https://www.dovepress.com/international-medical-case-reports-journal-journal
4 published pages including figures, diagrams and references. The manuscript management system is completely online and includes a very quick and fair peer-review system, which is all easy to use. Visit $\mathrm{http}: / / \mathrm{ww}$.dovepress.com/testimonials.php to read real quotes from published authors. 